13,05

\title{
Свойства ферромагнитных слоев CoPt для применения в спиновых светоизлучающих диодах
}

\author{
() А.В. Здоровейщев ${ }^{1}$, М.В. Дорохин ${ }^{1}$, О.В. Вихрова ${ }^{1}$, П.Б. Демина ${ }^{1}$, А.В. Кудрин ${ }^{1}$, \\ А.Г. Темирязев ${ }^{2}$, М.П. Темирязева ${ }^{2}$ \\ ${ }^{1}$ Научно-исследовательский физико-технический институт \\ Нижегородского государственного университета им. Н.И. Лобачевского, \\ Нижний Новгород, Россия \\ ${ }^{2}$ Фрязинский филиал Института радиотехники и электроники им. В.А. Котельникова РАН, \\ Фрязино, Россия
}

E-mail: zdorovei@nifti.unn.ru

\begin{abstract}
Проведено исследование магнитных свойств пленок $\mathrm{Co}_{45} \mathrm{Pt}_{55}$, полученных методом электронно-лучевого испарения в вакууме. Измерениями магнитооптических эффектов Фарадея и Керра подтверждено наличие оси легкого намагничивания, расположенной перпендикулярно поверхности $\mathrm{Co}_{45} \mathrm{Pt}_{55}$. Показано, что перпендикулярная магнитная анизотропия и остаточная намагниченность, сохраняются при $300 \mathrm{~K}$ в течение длительного времени. Методами магнитно-силовой микроскопии исследованы магнитные характеристики поверхности слоев $\mathrm{Co}_{45} \mathrm{Pt}_{55}$, обнаружены „круговые“ подвижные магнитные структуры. На основе гетеронаноструктур $\operatorname{In}(\mathrm{Ga}) \mathrm{As} / \mathrm{GaAs}$ сформированы спиновые светоизлучающие диоды с контактными слоями $\mathrm{Co}_{45} \mathrm{Pt}_{55}$, для которых регистрируется циркулярно-поляризованное излучение в отсутствие внешнего магнитного поля
\end{abstract}

Работа выполнена в рамках реализации государственного задания (проекты № 8.1054.2014/К и № 3.285.2014/К, ) Минобрнауки РФ, при поддержке РФФИ (гранты № 15-02-07824_a, 15-38-20642мол_а_вед и 16-07-01102_а) и гранта Президента РФ (МК-8221.2016.2).

\section{1. Введение}

Создание и исследование спиновых светоизлучающих диодов (ССИД) с циркулярно-поляризованным излучением, работающих в широком диапазоне длин волн $(0.9-1.3 \mu \mathrm{m})$, с возможностью функционирования в отсутствие внешнего магнитного поля, считается одной из важных научных задач в области спинтроники. При этом важным условием для функционирования ССИД является сохранение остаточной намагниченности ферромагнитного инжектора в направлении, перпендикулярном поверхности структур (геометрия Фарадея) [1,2]. В настоящей работе в качестве ферромагнитного инжектирующего контакта были применены материалы $[3,4]$, представляющие собой многослойные пленки сплава $\mathrm{Co}_{45} \mathrm{Pt}_{55}$. Особенностью исследуемых нами пленок является метод их получения - электронно-лучевое испарение в вакууме, что экономически более выгодно и проще технологически по сравнению с широко используемыми высоковакуумными методами получения пленок $\mathrm{CoPt}[3,5,6]$. Свойства пленок CoPt существенно зависят от технологических условий их получения: температуры осаждения, толщин формирующих сплав слоев Со и $\mathrm{Pt}$, времени последующего отжига, наличия тонкой диэлектрической прослойки между полупроводниковой структурой и наносимым металлическим слоем [4,7]. Ниже будут рассмотрены некоторые особенности магнитных свойств пленок $\mathrm{Co}_{45} \mathrm{Pt}_{55}$ и ССИД на основе гетеронаноструктур $\mathrm{In}(\mathrm{Ga}) \mathrm{As} / \mathrm{GaAs}$ с $\mathrm{Co}_{45} \mathrm{Pt}_{55}$ контактом Шоттки.

\section{2. Методика эксперимента}

Исследованные ССИД представляли собой гибридную структуру - ферромагнитный металл/туннельнотонкий диэлектрик/полупроводник. Полупроводниковая часть светоизлучающих диодов, представляющая собой гетероструктуру с квантовой ямой $\mathrm{InGaAs} / \mathrm{GaAs}$, была сформирована методом газофазной эпитаксии из металлоорганических соединений при атмосферном давлении водорода. После окончания эпитаксиального роста на поверхность структур методом электронно-лучевого испарения в высоком вакууме в едином технологическом процессе осаждался тонкий слой диэлектрика $\mathrm{Al}_{2} \mathrm{O}_{3}$ [7] и формировался контакт Шоттки на основе сплава $\mathrm{Co}_{45} \mathrm{Pt}_{55}$ [4]. Для создания такого сплава поочередно наносились слои $\mathrm{Pt}$ толщиной $0.5 \mathrm{~nm}$ и слои Со толщиной $0.3 \mathrm{~nm}$, температура нанесения варьировалась в пределах $200-400^{\circ} \mathrm{C}$, общая толщина пленки составляла $\approx 8 \mathrm{~nm}$.

Исследования структуры поверхности и магнитных свойств ферромагнитных пленок проводились методом магнитно-силовой микроскопии (МСМ) при помощи атомно-силового микроскопа SmartSPM (AIST-NT) с использованием зондов с пониженным магнитным моментом PPP-LM-MFMR, Nanosensors.

Магнитополевые зависимости угла Фарадея и поперечного эффекта Керра были исследованы посредством оригинальной автоматизированной установки изучения магнитооптических эффектов с использованием полупроводниковых лазерных диодов с длинами волны излучения $\lambda=980-1000 \mathrm{~nm}$ и $800 \mathrm{~nm}$ соответственно. При 
исследовании фарадеевского вращения внешнее магнитное поле прикладывалось перпендикулярно плоскости образца и совпадало с направлением распространения излучения лазера с $\lambda=980-1000 \mathrm{~nm}$. Арсенид-галлиевая структура имеет малый коэффициент поглощения излучения для такой длины волны (порядка $10 \mathrm{~cm}^{-1}$ ), что облегчает регистрацию магнитооптического эффекта Фарадея, обусловленного тонкой пленкой ферромагнитного металлического сплава. Получаемая зависимость угла поворота плоскости поляризации прошедшего лазерного излучения от магнитного поля определяется компонентой намагниченности пленки, перпендикулярной поверхности.

Геометрия эксперимента по наблюдению поперечного эффекта Керра предусматривает расположение внешнего магнитного поля в плоскости структуры, перпендикулярно направлению распространения падающего под углом $60-70^{\circ}$ от нормали к поверхности лазерного излучения. В данном случае удобно использовать лазер с $\lambda=800 \mathrm{~nm}$, чтобы повысить коэффициент отражения излучения. Регистрируемое относительное изменение интенсивности отраженного от намагниченной поверхности излучения определяется компонентой намагниченности в плоскости структуры.

Зависимости намагниченности структур со слоем $\mathrm{CoPt}$ от внешнего магнитного поля $(M(H))$ были получены при комнатной температуре с использованием магнитометра переменного градиента поля [8]. Максимальное значение магнитного поля составляло $1700 \mathrm{Oe}$.

Спиновые светоизлучающие диоды формировали путем нанесения CoPt-контакта через никелированную медную маску с отверстиями диаметром $d=500 \mu \mathrm{m}$, после чего химическим травлением формировали мезаструктуры. Измерения степени циркулярной поляризации электролюминесценции $\left(P_{\mathrm{EL}}\right)$ [7] изготовленных диодов проводились при температуре $20-300 \mathrm{~K}$ в криостате замкнутого цикла с электромагнитом. Магнитное поле варьировалось в диапазоне 0-3000 Ое и было приложено перпендикулярно плоскости структуры. В отсутствие магнитного поля (после предварительного намагничивания диодов) проводились исследования $P_{\mathrm{EL}}$ от времени.

\section{3. Экспериментальные результаты}

Наличие оси легкого намагничивания, расположенной перпендикулярно плоскости гетероструктуры $\mathrm{InGaAs} / \mathrm{GaAs}$ со слоем $\mathrm{Co}_{45} \mathrm{Pt}_{55}$, регистрировалось по магнитополевым зависимостям намагниченности и магнитооптическим характеристикам при комнатной температуре. В частности, была получена зависимость угла Фарадея от магнитного поля при прохождении через образцы лазерного излучения с длиной волны $980 \mathrm{~nm}$. На зависимости зарегистрирована петля гистерезиса с коэрцитивным полем около $160 \mathrm{Oe}$ (рис. 1 , кривая 1 ); в целом ее вид подобен магнитополевой зависимости намагниченности тех же структур (рис. 2, кривые 1 и 2 ).

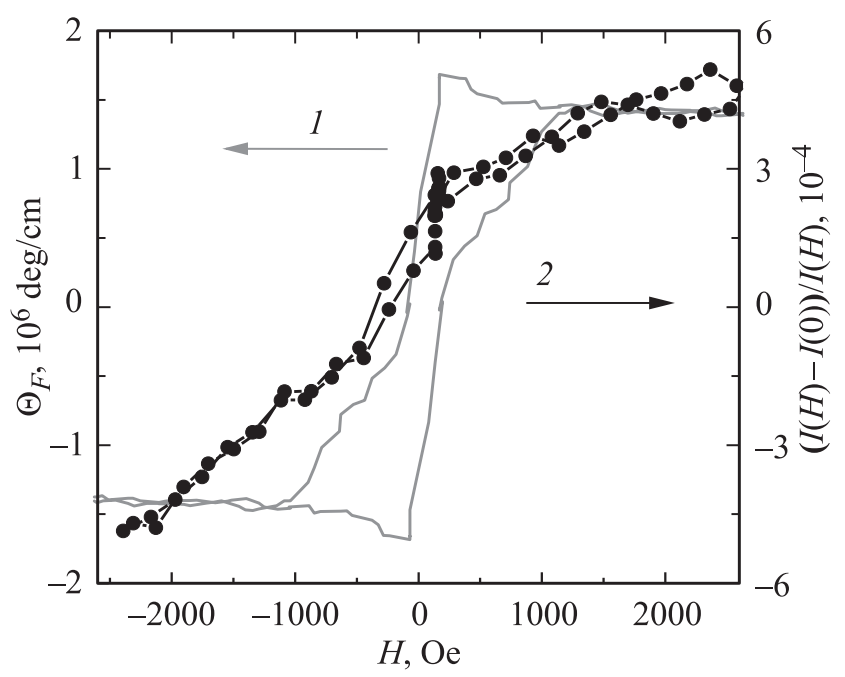

Рис. 1. Магнитополевые зависимости угла Фарадея (1), относительного изменения интенсивности излучения в поперечном эффекте Керра (2) для гетероструктуры, содержащей слой $\mathrm{Co}_{45} \mathrm{Pt}_{55}$. Измерения выполнены при комнатной температуре.

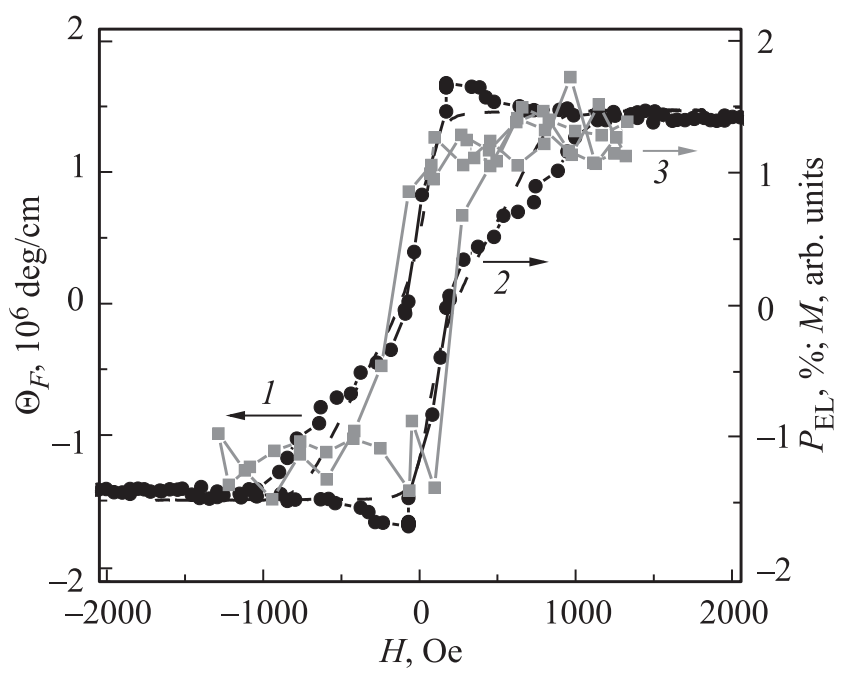

Рис. 2. Магнитополевые зависимости угла Фарадея (1), намагниченности (2) и степени циркулярной поляризации (3) [4] для гетероструктуры, содержащей слой $\mathrm{Co}_{45} \mathrm{Pt}_{55}$. Измерения выполнены при комнатной температуре.

В нулевом магнитном поле получены ненулевые значения угла Фарадея, что свидетельствует о сохранении остаточной намагниченности слоя $\mathrm{Co}_{45} \mathrm{Pt}_{55}$. Угол фарадеевского вращения достигал $1.5 \cdot 10^{6} \mathrm{deg} / \mathrm{cm}$ в магнитном поле менее 100 Ое. Наблюдаемое значение несколько превышает известные данные $-0.8 \cdot 10^{6} \mathrm{deg} / \mathrm{cm}$ (при $\lambda=980-1000 \mathrm{~nm}$ ) для пленок сплава $\mathrm{Co}_{50} \mathrm{Pt}_{50}$, толщиной $10-14 \mathrm{~nm}$, выращенных на кристаллах $\mathrm{MgO}$ [5].

Исследования поперечного магнитооптического эффекта Керра структур со слоями $\mathrm{Co}_{45} \mathrm{Pt}_{55}$ на поверхности также подтвердили расположение оси легкого намагничивания перпендикулярно плоскости структуры. 

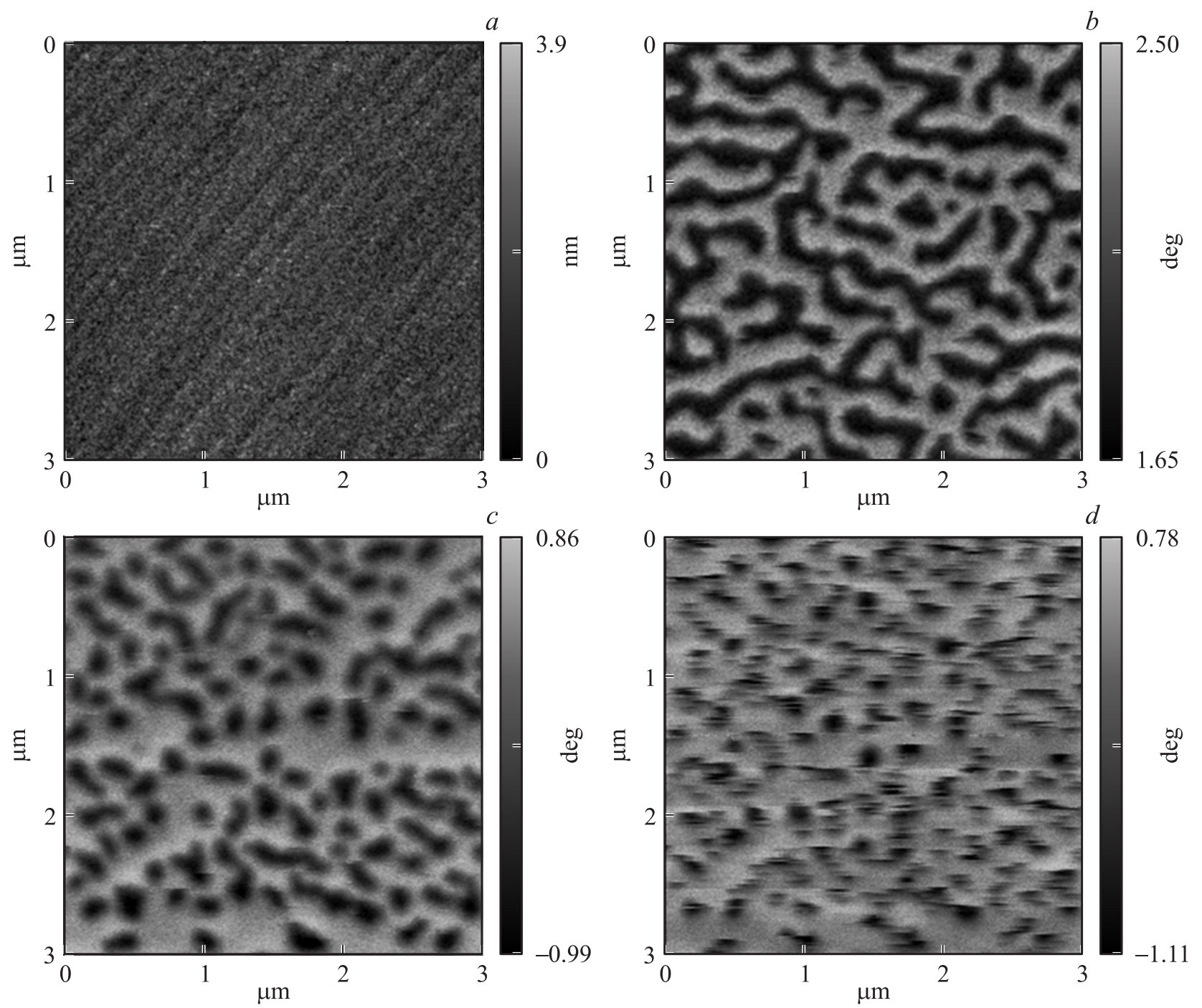

Рис. 3. Атомно-силовые изображения поверхности тонких $(\approx 8 \mathrm{~nm})$ пленок $\mathrm{Co}_{45} \mathrm{Pt}_{55}$, сформированных на поверхности

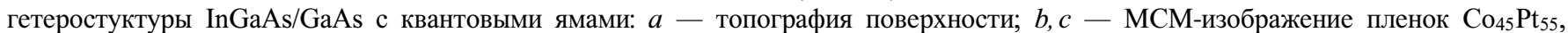

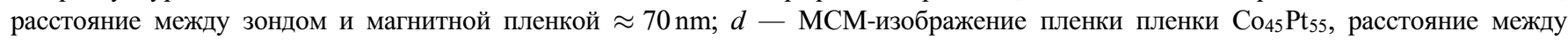
зондом и магнитной пленкой $\approx 50 \mathrm{~nm}$.

Магнитополевая зависимость относительного изменения интенсивности отраженного от намагниченной поверхности лазерного излучения не содержит петли гистерезиса и не выходит на насыщение в диапазоне используемых магнитных полей $( \pm 4000$ Ое) (рис. 1 , кривая 2$)$. Эти данные также коррелируют с результатами изучения намагниченности при приложении внешнего магнитного поля в плоскости структуры [4].

Проведено исследование зависимости остаточной намагниченности слоя $\mathrm{Co}_{45} \mathrm{Pt}_{55}$ от времени. Структура при этом намагничивалась полем $1700 \mathrm{Oe}$, приложенным перпендикулярно поверхности пленки, затем внешнее магнитное поле выключалось, и измерялась зависимость намагниченности от времени на магнетометре переменного градиента магнитного поля. Обнаружено, что величина намагниченности сохраняется в течение длительного (более $72 \mathrm{~h}$ ) времени.
Для исследованных гетероструктур InGaAs/GaAs c осажденным слоем $\mathrm{Co}_{45} \mathrm{Pt}_{55}$ была характерна структура поверхности, приведенная на рис. 3, $a$. Видно, что поверхность такой пленки достаточно ровная и однородная, среднеквадратичное значение высоты неровностей $(R M S)$ составляло $\approx 0.5 \mathrm{~nm}$, на поверхности прослеживаются полосы, повторяющие неровности исходной вицинальной поверхности полупроводниковой гетероструктуры. При измерении исходных образцов (заранее не намагниченных) в МСМ-режиме (рис. $3, b, 3, c$ ) были зарегистрированы несколько характерных видов магнитных структур. Это были „лабиринтные“ (рис. $3, b$ ) либо „круговые“ магнитные структуры с типичным диаметром $\approx 100 \mathrm{~nm}$ (рис. $3, c$ ). В ряде случаев доменная структура отсутствовала (на рисунках не представлено), пленки были намагничены однородно. Поскольку поверхность пленок $\mathrm{Co}_{45} \mathrm{Pt}_{55}$ была ровной, такие раз- 
личия магнитных картин не связаны с особенностями топографии поверхности.

Большинство исследованных нами магнитных пленок легко перемагничивалось полем зонда. Чтобы уменьшить влияние зонда, магнитные структуры измерялись в один проход. Первоначальное сканирование проводилось при достаточно большом расстоянии (около $200 \mathrm{~nm}$ ) между зондом и образцом. Далее, мы постепенно уменьшали расстояние до поверхности. Изображения, представленные на рис. $3, b, c$ получены при расстоянии $\approx 70 \mathrm{~nm}$. Уменьшение расстояния до $50 \mathrm{~nm}$ (рис. 3,d) приводит к появлению характерных полос, свидетельствующих о смещении отдельных магнитных структур в слабом магнитном поле зонда. При последующем сканировании на большем расстоянии положение и плотность „круговых“ магнитных структур изменялись. После намагничивания образцов во внешнем магнитном поле, направленном по нормали к поверхности, МСМ-измерения, как правило, показывают отсутствие магнитных доменов, т.е. пленки обладают остаточной намагниченностью. При этом полем зонда можно было локально перемагнитить участок пленки, приблизив зонд к образцу. Любопытно отметить, что наблюдавшиеся нами „круговые“ магнитные структуры, напоминают структуры пленок ферритов-гранатов с цилиндрическими магнитными доменами [9], за исключением того что в нашем случае характерные размеры были на несколько порядков ниже. Магнитные структуры, по размерам, типам и подвижности подобные наблюдаемым нами, сравнительно недавно были описаны в [10]. При этом картина на рис. $3, b$ может соответствовать полосовой структуре магнитной геликоидной спирали, находящейся в небольшом магнитном поле, а картина на рис. $3, c-$ системе магнитных вихрей (скирмионов). Поскольку в отличие от [10] нами были зарегистрированы достаточно устойчивые магнитные картины при комнатной температуре и в отсутствие внешнего подмагничивания, можно утверждать, что в тонких пленках $\mathrm{Co}_{45} \mathrm{Pt}_{55}$ наблюдаются магнитные структуры, обладающие свойствами цилиндрических магнитных доменов [9] и свойствами системы магнитных вихрей [10]. Вероятно, такие особенности тонких пленок $\mathrm{Co}_{45} \mathrm{Pt}_{55}$ обусловлены наличием перпендикулярной магнитной анизотропии. Этот вопрос требует дополнительного исследования.

Полученные пленки $\mathrm{Co}_{45} \mathrm{Pt}_{55}$, были применены в качестве ферромагнитного металлического инжектора для создания ССИД на основе гетероструктуры с квантовой ямой InGaAs/GaAs [4]. Вид магнитополевой зависимости степени циркулярной поляризации электролюминесценции таких диодов (рис. 2, кривая 3) подобен зависимостям угла вращения Фарадея (кривая 1) и намагниченности (кривая 2) от приложенного магнитного поля. Исследование временно́й эволюции $P_{\mathrm{EL}}$ (аналогично методике измерения зависимости намагниченности от времени) показало неизменность эффекта в течение более $2 \mathrm{~h}$. Следовательно, можно заключить, что нами был сформирован спиновый светоизлучающий диод, функционирующий в отсутствие внешнего магнитного поля, благодаря наличию остаточной намагниченности в слое $\mathrm{Co}_{45} \mathrm{Pt}_{55}$.

\section{4. Заключение}

Таким образом, сформированы и исследованы ферромагнитные контактные слои на основе сплава $\mathrm{Co}_{45} \mathrm{Pt}_{55}$ для применения в спиновых светоизлучающих диодах. Измерения магнитооптических эффектов (эффекта Фарадея и поперечного эффекта Керра) подтверждают наличие оси легкого намагничивания, расположенной перпендикулярно плоскости пленки $\mathrm{Co}_{45} \mathrm{Pt}_{55}$. Представлены данные АCМ-исследований топографии поверхности и магнитно-силовой микроскопии. Показана возможность использования слоев $\mathrm{Co}_{45} \mathrm{Pt}_{55}$ для создания магнитонезависимых спиновых светоизлучающих диодов, функционирующих при комнатной температуре.

Авторы выражают глубокую благодарность ведущему научному сотруднику НИФТИ ННГУ Б.Н. Звонкову за выращивание полупроводниковых гетеронаноструктур.

\section{Список литературы}

[1] S. Hövel, N.C. Gerhardt, M.R. Hofmann, F.-Y. Lo, A. Ledwig, D. Reuter, A.D. Wieck, E. Schuster, H. Wende, W. Keune, O. Petracic, K. Westerholt. Appl. Phys. Lett. 93, 021117 (2008).

[2] S. Hövel, N.C. Gerhardt, M.R. Hofmann, F.-Y, Lo, D. Reuter, A.D. Wieck, E. Schuster, W. Keune, H. Wende, O. Petracic, K. Westerholt. Appl. Phys. Lett. 92, 242102 (2008).

[3] H. Sato, T. Shimatsu, Y. Okazaki, H. Muraoka, H. Aoi, S. Okamoto, O. Kitakami. J. Appl. Phys. 103, 07E 114 (2008).

[4] А.В. Здоровейщев, М.В. Дорохин, П.Б. Демина, А.В. Кудрин, О.В. Вихрова, М.В. Ведь, Ю.А. Данилов, И.В. Ерофеева, Р.Н. Крюков, Д.Е. Николичев. ФТП 49, 1649 (2015).

[5] Е.М. Артемьев, М.Е. Артемьев. ФТТ 52, 2128 (2010).

[6] M. Yu, H. Ohguchi, A. Zambano, I. Takeuchi, J.P. Liu, D. Josell, L.A. Bendersky. Mater. Sci. Eng. B 142, 139 (2007).

[7] А.И. Бобров, Ю.А. Данилов, М.В. Дорохин, А.В. Здоровейщев, Н.В. Малехонова, Е.И. Малышева, Д.А. Павлов, С. Сайед. Поверхность 7, 57 (2015).

[8] P.J. Flanders. J. Appl. Phys. 63, 3940 (1988).

[9] Э. Бобек, Э. Делла Торре. Цилиндрические магнитные домены. Энергия, М. (1977). 192 с.

[10] X.Z. Yu, Y. Onose, N. Kanazawa, J.H. Park, J.H. Han, Y. Matsui, N. Nagaosa, Y. Tokura. Nature 465, 901 (2010). 